\title{
Toxicity assessment of meat-processing wastewater
}

\author{
Olga Ivanchenko ${ }^{1, *}$, Rustem Khabibullin ${ }^{2}$, Thao Le Huong ${ }^{2}$, Petr Balanov ${ }^{3}$ and Irina Smotraeva ${ }^{3}$ \\ ${ }^{1}$ Peter the Great St.Petersburg Polytechnic University (SPbPU), 195251, Politekhnicheskaya Str., 29, St.Petersburg, Russia \\ ${ }^{2}$ Kazan National Research Technological University (KNRTU), 420015, K.Marks Str., 68, Kazan, Russia \\ ${ }^{3}$ ITMO University, 197101, Kronverksky Pr. 49, Saint Petersburg, Russia
}

\begin{abstract}
The development of industrial waste treatment and disposal technologies requires the use of rapid analyses for quick and accurate assessment of the properties of waste and wastewater. Biotests allows quickly define the integral toxicity and can be attractive for screening studies. The purpose of this paper was to study the toxicity of samples of wastewater from a meat-processing plant at various test sites for a comprehensive assessment of their danger to surrounding ecosystems and the biocenosis of biological treatment facilities. The study of meat-processing wastewater, as well as its fractions, did not reveal signs of their strong toxic potential. The optimal method for studying the total toxicity of complex mixtures is to evaluate the properties of the water-soluble fraction, since it is a real threat if it enters the human body. Biotests on representatives of various trophic levels made it possible to estimate the safety of the studied wastewater in a short time, therefore were recommended as test systems for monitoring the environmental safety of wastewater in order to identify a number of individual chemical compounds, integral toxic potential, and long-term consequences for natural and artificial ecosystems.
\end{abstract}

\section{Introduction}

The solution of the environmental problems of food enterprises is complex now, as evidenced by the wide range of technologies used, including biological ones [1$3]$.

Food-processing plants and meat-processing plants particularly are powerful sources of anthropogenic effects on natural water ecosystems. These wastewaters have complex multi-component composition that include proteins, fats, non-protein nitrogen compounds and minerals. Discharge of these contaminants into surface waters resulting in unpleasant smell and taste is unacceptable if water is intended for household and food needs.

Meat-processing wastewater represents an diluted emulsions with high aggregation and sedimentation stability. More than $70 \%$ of the contaminants are fat-protein complexes. According to the phase-dispersion state, $20 \%$ are settling, about $40 \%$ are supercolloid, about $20 \%$ are colloidal and $20 \%$ are soluble impurities.

Although the chemical composition of meatprocessing wastewater of different plants and countries varies slightly, but they are characterized by high content of organic substance, which allows them to be used as a potential source of fertilizer, technical fat and protein concentrate.

Development of technologies of wastewater treatment and industrial wastes recycling is based on data on chemical composition and toxic properties of facilities, which requires the use of rapid analytical control methods [4-7]. The main indicators of wastewater contamination are color, odor, medium reaction $(\mathrm{pH})$, dry residue content, suspended particulate content, biological oxygen demand (BOD) and chemical oxygen demand (COD) [8]. To date, the quality of wastewater is regulated by bacteriological, chemical and parasitological indicators, which cannot be assessed quickly. In addition, in most cases safety is determined by the permissible concentrations accepted for individual chemicals. However, in nature, biological objects not affected by individual compounds, but by a whole complex of substances, which affect each other causing antagonistic and synergistic effects, so the assessment of water quality by integral indicators seems to be the most promising approach to determining the real environmental safety of wastewater [9-11].

One of the tools for assessing the integral effects of multi-component anthropogenic toxicants on natural ecosystems and living organisms is the determination of their toxicity and mutagenic activity.

In the system of monitoring the state of natural environments and ecosystems, biotests play an increasingly important and relevant role, which makes it possible to quickly assess the integral assessment of toxicity, which makes its use very attractive in screening studies [12, 13].

Various aquatic organisms - seaweed, microorganisms, invertebrates, fishes - are used for biotests. The most popular objects are plankton crustaceans, for example Daphnia magna, and to date there are a number of works to determine the impact of xenobiotics on this test object $[14,15]$. Besides, on sensitivity and degree of study it is possible to allocate microscopic monocelled

\footnotetext{
* Corresponding author: obivanchenko@yandex.ru
} 
green seaweed (Scenedesmus guadricauda, Chrorella sp.) and small aquarian and native fishes [16]. Important conditions of proper biotests are: genetic uniformity of laboratory cultures, regular checking of sensitivity, keeping under constant recommended laboratory conditions, stipulated by standards. All this ensures necessary convergence and reproducibility of researches results and maximal sensitivity to toxic substances. A set of standard methods, regulated by the relevant legislative framework, determines test objects necessary to biotests of certain objects.

With these test objects in mind, the biotests techniques allow to determine of more than $80 \%$ of dangerous substances.

Each of these objects has its own advantages and limitations, but none of the organisms can serve as a universal and to provide the same sensitivity to all pollutants, so it is difficult to give preference to one method and test object. It is necessary to choose methods and objects that correspond to specific task and allow to prove adequacy of the chosen method to the object of research.

Studies of toxic properties of various industrial enterprises wastewater in multilevel test systems are carried out around the world, which are aimed at practical implementation of methods of analysis of toxicity and genotoxicity of wastewater [17-19].

The purpose of this paper was to study the toxicity of wastewater samples from a meat-processing plant at various test sites for a comprehensive assessment of their danger to surrounding ecosystems and the biocenosis of biological treatment facilities.

\section{Materials and methods}

The native wastewater has been studied as well as its ether and water fractions.

The ether fraction was obtained by extraction of wastewater with diethyl ether, evaporation of the ether layer to dryness and dissolution of the solid residue in dimethyl sulfoxide (DMSO). After dissolving the residue, $1 \mathrm{ml}$ of DMSO contained an extract of $5 \mathrm{ml}$ of native wastewater.

The aqueous fraction was a residue of native wastewater after extraction with ether. Sample sterilization was carried out by filtration through sterile Synpor filters with a pore diameter of $0.45 \mu \mathrm{m}$.

\subsection{Toxicity biotest on branch cancers Daphnia magna}

An experiment to establish acute toxic action was conducted by biotests the original test water without dilution and several dilutions thereof. The studies were carried out in 150-200 $\mathrm{cm} 3$ beakers, which filled $100 \mathrm{~cm} 3$ of the test water, and were filled with 10 daphnium of no more than 24 hours age (determined by the size of the cancers). In a separate beaker, cancers were deposited with an age of more than 24 hours after filtration through a net set, and then caught with a pipette (with a sawn and melted end) of $2 \mathrm{cc}$ with a rubber pear. Daphnias were introduced into a glass of water under investigation. 3 cups were used for each series of test water. The total number of cups used in the experiments is equal to the triple sum of all dilutions plus 3 for the test water and 3 for the control. In experiments to determine acute toxicity, daphnia was not fed.

In order to eliminate the possible effect of dissolved oxygen fluctuation on the results of daphnium survival, all further studies were carried out on saturation of the investigated water with air oxygen. 48 hours later, the surviving daphnia were counted.

The percentage of daphnium deaths (A, \%) in the test water was calculated as compared to the control according to the equation:

$$
A=\frac{X_{c o n t r}-X_{\text {exp }}}{X_{c o n t r}} \cdot 100 \%,
$$

where $X_{\text {contr }}$ is the number of surviving daphnias in control; $\mathrm{X}_{\text {exp }}$ is the number of daphnium survivors in the water being tested.

At $\mathrm{A} \leq 10 \%$ the tested water has no intense toxic effect. At $\mathrm{A} \geq 50 \%$ the tested water has intense toxic effect.

Determination of dissolved oxygen content in water was performed on oximeter (HI 9143, Hannah Instruments).

\subsection{Phytotoxicity on red radish with a white tip seeds}

The determination of toxicity by seed germination rate was performed on red radish (Raphanus sativus var. radicula) seeds. 50 seeds were spread onto filter paper in Petri dishes and poured with $5 \mathrm{ml}$ of test wastewater. The experiments were carried out 4-5 times. The plates were allowed to stand at $20^{\circ} \mathrm{C}$. Seed germination rate was evaluated three times per day for 72 hours. If the seeds in the test water did not germinate as compared to the con-trol or the root length as a percentage of the control is below $70 \%$, the water is toxic and not suitable for irriga-tion. Threshold 70 is because soil reduces the inhibitory effect of toxic water components due to its sorption ca-pacity. With roots longer than $120 \%$ of the control, water is assumed to have stimulating properties. Spring water was used as a control.

\subsection{Toxicity to microorganisms}

Toxic properties of water and its components were determined by comparing the growth of strains of microorganisms on a full nutrient medium both in the presence of the tested samples (experimental variants) and in their absence (control variant). Cells of Escherichia coli and Sarcina sp., typical gram-negative and gram-positive representatives of the water and soil microflora, were used as test objects. 12-15 hours before the experiment the strain culture was transferred sterically from the beveled nutrient agar to tubes with $5 \mathrm{ml}$ of meat-peptone broth (MPB) to obtain a seed culture. $3 \mathrm{ml}$ of wastewater and $0.6 \% \mathrm{ml}$ of bacterial suspension were added to tubes 
with $0.1 \mathrm{ml}$ of 0.1 melted and cooled to $45^{\circ} \mathrm{C}$ meatpeptone agar (MPA), and $0.1 \mathrm{ml}$ of solvent was added in a negative control. The contents of the tube were mixed and laminated onto the surface of the MPA in Petri dishes. The plates were incubated for 24 hours at $37^{\circ} \mathrm{C}$ and the number of colonies was then counted.

Toxicity was assessed by survival rate (\%), defined as the ratio of the colonies number in the test to the number of colonies in the control according to the equation:

$$
B=\frac{X_{\exp }}{X_{\text {contr }}} \cdot 100 \% \text {, }
$$

where $\mathrm{B}$ is the survival rate, $\mathrm{X}_{\exp }$ is the number of colonies in the experiment, $\mathrm{X}_{\text {contr }}$ is the number of colonies in control.

The experiments were carried out in triplicate. The statistical validity of the difference in the average values compared was determined by the standard Student $\mathrm{t}$ criterion.

\section{Results and Discussion}

Chemical composition of waste water from meatprocessing plants in different countries. Research by New Zealand scientists has shown that the wastewater of their meat-processing plants after primary purification is rich in nutrients, has a COD of $800-2000 \mathrm{mg} / \mathrm{l}$ and contains nitrogen in an amount of 75-200 mg/l, phosphates - 20-40 mg/l [20]. Waste water of meatprocessing plants of Brazil has another composition: $\mathrm{pH}$ $=6.3-6.6, \mathrm{COD}-2000-6000 \mathrm{mg} / \mathrm{l}$, BOD -1300-2300 $\mathrm{mg} / \mathrm{l}$, fat - 40-600 mg/l, soluble salts - 850-6300 mg/l [21]. The wastewater under study had a COD of 1773.3 $\mathrm{mg} \mathrm{O}$ per liter, fat $-95 \mathrm{mg} / \mathrm{l}$.

Meat-processing wastewater is rich in organic components that leads to intensive microbial and chemical oxidation, which involve consumption of oxygen dissolved in water [19-21]. The dissolved oxygen content of the native wastewater and its dilution was therefore determined. The results of the tests are shown in Table 1.

Table 1. Dissolved oxygen content in wastewater during its dilution.

\begin{tabular}{|c|c|c|c|c|c|}
\hline $\begin{array}{c}\text { Investigated } \\
\text { object }\end{array}$ & $\begin{array}{c}\text { Native } \\
\text { wastewater }\end{array}$ & \multicolumn{3}{|c|}{$\begin{array}{c}\text { Wastewater } \\
\text { dilution }\end{array}$} & \multirow{2}{*}{ Control } \\
\cline { 3 - 5 } & & $\mathbf{1 : 1}$ & $\mathbf{1 : 2}$ & $\mathbf{1 : 3}$ & \\
\hline $\begin{array}{c}\mathrm{O}_{2} \text { content, } \\
\mathrm{mg} / \mathrm{dm}^{3}\end{array}$ & 0.1 & 1.6 & 2.2 & 4.5 & 7.5 \\
\hline
\end{tabular}

As shown in Table 1, dilution of native wastewater, very poor in dissolved oxygen, with water resulted in its enrichment with dissolved oxygen. In order to eliminate the possible effect of dissolved oxygen fluctuation on daphnia survival results, all further studies were carried out after air oxygen saturation of the investigated water.

Results of determination of acute toxicity of meatprocessing plants wastewater are given in Table 2 .
The results of the study of the toxicity of water to branch cancers of Daphnia magna after 48 hours of cultivation show that the minimum dilution at which wastewater did not have acute toxic effect is 1:100 (Table 2). At 1:80 dilution a weak toxic effect was detected. Diluted 1:60, 1:40 and 1:20 wastewater had acute toxic effects, and when diluted 1:3, 1:2, 1:1 and without dilution (native state) the wastewater resulted in $100 \%$ of cancer death.

The results clearly indicate the toxicity of the wastewater sample taken during the winter (February), while in the spring sample (April) there was no toxicity already in the single dilution of water. Thus, the toxicity of wastewater to Daphnia magna is a labile characteristic requiring regular analytical control.

Table 2. Acute toxicity of wastewater to Daphnia magna.

\begin{tabular}{|c|c|c|}
\hline Test samples & $\begin{array}{c}\text { Percentage of } \\
\text { daphnia deaths } \\
\text { A (\%) }\end{array}$ & $\begin{array}{c}\text { Dissolved } \mathrm{O}_{2} \\
\text { concentration } \\
\mathrm{mg} \mathrm{dm}^{-3}\end{array}$ \\
\hline \multicolumn{3}{|c|}{ February } \\
\hline Control & 0 & 7.5 \\
\hline Native wastewater & 100 & 0.1 \\
\hline Wastewater diluted: & & \\
\hline $1: 1$ & 100 & $1.6 \pm 0.2$ \\
\hline $1: 2$ & 100 & $2.2 \pm 0.3$ \\
\hline $1: 3$ & 100 & $4.5 \pm 0.4$ \\
\hline $1: 20$ & 99.0 & \\
\hline $1: 40$ & 92.5 & \\
\hline $1: 60$ & 50.0 & \\
\hline $1: 80$ & 20.0 & \\
\hline $1: 100$ & 0 & \\
\hline \multicolumn{3}{|c|}{ April } \\
\hline Control & 0 & 7.4 \\
\hline Native wastewater & 70 & 0.1 \\
\hline Wastewater diluted: & & \\
\hline $1: 1$ & 18.0 & $1.9 \pm 0.2$ \\
\hline $1: 2$ & 12.0 & $2.8 \pm 0.4$ \\
\hline $1: 3$ & 6.0 & $6.5 \pm 0.6$ \\
\hline $1: 20$ & 0 & \\
\hline
\end{tabular}

Due to the possibility of using contaminated waters for irrigation of agricultural land, it is recommended to study their impact on cultural plants before application. For this purpose phytotoxicity of water is determined, which is estimated by degree of seed germination inhibition, growth of seedlings, roots or by reduction of seed germination energy. Red radish with a white tip seeds were used in the experiment and native wastewater was investigated in a 1:1 dilution as well. The test results are shown in Table 3.

Table 3. Phytotoxicity of investigated wastewater.

\begin{tabular}{|c|c|c|c|c|}
\hline \multirow[t]{2}{*}{ Sample } & \multicolumn{3}{|c|}{$\begin{array}{c}\text { Number of germinated } \\
\text { seeds, } \% \text {, after }\end{array}$} & \multirow[t]{2}{*}{$\begin{array}{c}\text { Germination } \\
\text { energy }\end{array}$} \\
\hline & $24 \mathrm{~h}$ & $48 \mathrm{~h}$ & $72 \mathrm{~h}$ & \\
\hline Control & 96.0 & 98.0 & 100.0 & 10.55 \\
\hline Wastewater & 89.5 & 95.0 & 96.5 & 9.50 \\
\hline $\begin{array}{l}\text { Wastewater } \\
\text { diluted } 1: 1\end{array}$ & 91.1 & 96.5 & 96.5 & 9.50 \\
\hline
\end{tabular}

From the data presented above it can be seen that the wastewater under study only affected the production of radish seeds on the first day of the test. After 72 hours, 
the number of germinated seeds in native wastewater and 1:1 dilution was equalized. In general, the study showed no suppression of seed germination by the sample under study. In determining germination energy, the results with radish seeds are slightly greater in the control germination energy than in samples with wastewater. It can be con-cluded from this that substances capable of inhibiting seed germination are present in wastewater.

Cultures of bacteria Escherichia coli and Sarcina sp. were used for assessment of antibacterial toxicity of wastewater. These microorganisms are natural inhabitants of natural biocenoses, but have differences in the cell wall structure. It is generally accepted that the suppression of the microorganisms growth more than $50 \%$ is an indicator of toxicity, and such wastewater has an adverse effect on biocenosis as a whole.

The results of the test are shown in Table 3.

Table 3. Toxicity of wastewater to bacteria.

\begin{tabular}{|c|c|c|c|c|}
\hline \multirow{2}{*}{ Microorganism } & \multicolumn{4}{|c|}{ Survival, \% } \\
\cline { 2 - 5 } & Control & $\begin{array}{c}\text { native } \\
\text { effluent }\end{array}$ & $\begin{array}{c}\text { organic } \\
\text { fraction }\end{array}$ & $\begin{array}{c}\text { aqueous } \\
\text { fraction }\end{array}$ \\
\hline Escherichia coli & 100 & 92.0 & 95.2 & 90.0 \\
\hline Sarcina sp. & 100 & 93.0 & 99.1 & 96.7 \\
\hline
\end{tabular}

Experiments revealed that the wastewater under study had little effect on the survival of the microorganisms Sarcina sp. and E. coli. Cell survival in the trial was close to $100 \%$ relative to control. It should be noted that E. soli cells were more sensitive to native runoff and its constituents. The maximum toxic effect recorded in the trial was $10 \%$.

The aqueous moiety remaining after removal of the organic fraction from the wastewater showed greater tox-ic properties than the organic extract and native wastewater. However, even under these experimental conditions, the maximum toxic effect recorded was $10 \%$.

Wastewaters of food-processing and meat-processing in addition to biological origin substances (protein, amino acids, fat, etc.) contain a huge amount of chemically synthesized compounds. Among them are residues of food additives, improving agents, structureand color stabilizers (nitrites, phosphates), as well as detergent and disinfectants used in production and washed with water. They can significantly increase the toxicity of the wastewater composition [22-23].

\section{Conclusions}

Thus, the study of the wastewater of meat-processing and production plants, as well as their fractions with hydrophilic and lipophilic properties, did not reveal signs of their strong toxic potential.

From both a biological and hygienic point of view, the best method of studying the total toxicity of complex mixtures - soil pollutants and water bodies - is to evaluate aqueous extracts, as it is the water-soluble fraction that poses a real threat to the human body as a result of washing into groundwater, transition to plants, etc.
Thus, the biotests used in the work, including representatives of different trophic levels, allowed to fully assess the safety of the studied wastewater of the plant in a short period of time when choosing the method of their removal and disposal and can be recommended as test systems in monitoring the environmental safety of wastewater. Economic pressure from the supervisory authorities forces enterprises to find efficient, reliable in operation treatment facilities, which guarantee stable and high quality of cleaning, or reconstruction, modernization or expansion of existing ones.

Chemical analyses of the pollutants listed in the water quality standards are not sufficient to identify cause-effect pollutants with harmful biological effects, and single-point biotests may underestimate adverse effects.

It seems to be useful to conduct an wastewater integrated analysis in a number of test systems in order not only to detect certain chemical and biological compounds, but also to assess the integrated effects on ecosystems in a short time.

\section{References}

[1] M.E. Grismer, Ch.C. Ross, G.E. Valentine Jr., B.M. Smith, J.L. Walsh Jr., Wat. Environ. Res., 74 (2002).

[2] A. Aziz, F. Basheer, A. Sengar, Irfanullah, S.U. Khan, I.H. Farooqi, Sci. of the Tot. Environ., 686 (2019).

[3] E. Sroka, W. Kamiński, J. Bohdziewicz, Desalination, 162 (2004).

[4] I.S. Arvanitoyannis, L. Demetrios, Int. Journ. of Food Sci. \& Techn., 43 (2007).

[5] I.S. Arvanitoyannis, L. Demetrios, Waste Management for the Food Industries, Academic Press (2008).

[6] O. Ivanchenko, R. Khabibullin, R. Bhat, EECE2018, 245 (2018).

[7] R. Khabibullin, T.L. Huong, O. Ivanchenko, A. Petrov, E3S Web of Conferences, 140 (2019).

[8] H. Insam, M. Gómez-Brandón J. Ascher-Jenull, The Future of Soil Carbon (2018).

[9] V. Saffiotti, Environ. Health Perspect., 47 (1983).

[10] L. Cizmas, T.J. McDonald, T.D. Phillips, A.M. Gillespie, R.A. Lingenfelter, L.F. Kubena, K.C. Donnelly, Environ. Sci. Technol., 38 (2004).

[11] F.D. Leusch, S.J. Khan, M.M. Gagnon, P. Quayle, T. Trinh, H. Coleman, C. Rawson, H.F. Chapman, P. Blair, H. Nice, T. Reitsema, Water.Res., 50, 1, 420-431 (2014).

[12] B. Zegura, E. Heath, A. Cemosa, M. Filipic, Chemosphere, 75 (11), 1453-1460 (June 2009).

[13] E.N. Esimbekova, A.M. Kondik, V.A. Kratasyuk, Environ. Monit. Assess., 185, 7, 5909-5916 (2013).

[14] J. Martins, L. Oliva Teles, V. Vasconcelos, Environ Int., 33 (2007).

[15] O. Klebercz, W.M. Mayes, A.D. Anton, V. Feigl, A.P. Jarvis, K. Gruiz., J. Environ. Monit., 14 (2012). 
[16] J.S. Ra, H.K. Kim, N.I. Chang, S.D. Kim, Environ. Monit. Assess., 129 (2007).

[17] F.P. Rodrigues, J.P.F. Angeli, M.S. Mantovani, C.L.B. Guedes, B.Q. Jordao, Genet. Mol. Biol., 33 (2010).

[18] Y. Han, N. Li, Y. Oda, M. Ma, K. Rao, Z. Wang, W. Jin, G. Hong, Z. Li, Y. Luo, Ecotoxicol, Environ. Saf., 133 (2016).

[19] C.P.N. Rampley, P.G. Whitehead, L. Softley, M.A. Hossain, L. Jin, J. David, S. Shawal, P. Das, I.P. Thompson, W.E. Huang, R. Peters, P. Holdship, R. Hope, G. Alabaster, Sci. Total Environ., 703 (2020).

[20] N. Thayalakumaran, R. Bhamidimarri, P.O. Bickers, Water Sci Technol., 48 (2003).

[21] C.E. Caixeta, M.C. Cammarota, A.M. Xavier, Bioresour Technol., 81 (2002).

[22] A. Fiorentino, A. Gentili, M. Isidori, M. Lavorgna, A. Parrella, F. Temussi, J Agric Food Chem., 52 (2004).

[23] W.L. Gong, K.J. Sears, J.E. Alleman, E.R. Blatchley, 3rd. Environ. Toxicol. Chem., 23 (2004). 